\title{
Elucidation of the Discharge Mechanism of CuO Cathode Material
} in Alkaline Electrolyte

\author{
Timothy W. Jones, Mark R. Bailey,* and Scott W. Donne ${ }^{z}$ \\ Discipline of Chemistry, University of Newcastle, Callaghan 2308 NSW. Ausiralia
}

\begin{abstract}
Two CuO materials were synthesized having vastly different physico-chemical properties - one being amorphous with a high BET surface area, while the other is a low-area crystalline material. Linear sweep voltammetry characterization in a $9.0 \mathrm{M} \mathrm{KOH}$ electrolyte revealed markedly different discharge behavior in terms of reaction pathway, with the amorphous material undergoing a two-step process and the crystalline material a single step process. Investigation into the mechanism of the discharge of the amorphous CuC suggests a possible dissolution/re-precipitation route. This was confirmed by direct electrochemical detection of the soluble reduced intermediate. Confirmation of this mechanism explained the different reaction pathway followed by the crystalline sample, as the material is kinetically inert to the solubilization step in the mechanism, forcing it to discharge via an altogether different two-electron pathway.

(3) 2013 The Electrochemical Society. [DOI: 10.1149/2.072304jes] All rights reserved.
\end{abstract}

Manuscript submitted January 4, 2013; revised manuscript received February 4, 2013. Published February 22, 2013.

Increasing the power density of primary cathode materials remains a relevant challenge in battery material research. Although present in the patent literature, ${ }^{1,2}$ little scientific description of $\mathrm{CuO}$ as a cathode material exists. Recently we have reported a study on a promising novel $\mathrm{CuO}$ material which possesses superior discharge performance to electrolytic manganese dioxide sample under high rate galvanostatic discharge conditions greater than $600 \mathrm{mAg}^{-1}$.

The CuO material discharged via a two-step pathway. By analogy with $\mathrm{AgCuO}_{2},{ }^{1-4}$ in which $\mathrm{CuO}$ is a discharge intermediate, the material was understood to follow the pathway:

$$
\begin{aligned}
& 2 \mathrm{CuO}+\mathrm{H}_{2} \mathrm{O}+2 \mathrm{e}^{-} \rightarrow \mathrm{Cu}_{2} \mathrm{O}+2 \mathrm{OH}^{-} \\
& \mathrm{Cu}_{2} \mathrm{O}+\mathrm{H}_{2} \mathrm{O}+2 \mathrm{e}^{-} \rightarrow 2 \mathrm{Cu}^{0}+2 \mathrm{OH}^{-}
\end{aligned}
$$

The theoretical specific capacity of each step is $337 \mathrm{mAh} \mathrm{g}^{-1}$. The adoption of this mechanism was based on the fact that if $\mathrm{CuO}$ were reduced directly to $\mathrm{Cu}^{0}$, then there would be no peak corresponding to Eqn 2 . However, a second peak of capacity of $265 \mathrm{mAh} \mathrm{g}^{-1}$ was observed, which is too large to be ascribable as a synthesis impurity which escaped X-ray diffraction detection. The second voltametric peak was therefore ascribable to $\mathrm{Cu}_{2} \mathrm{O}$ electrochemically generated as a discharge intermediate by Eqn. 1, without direct or further evidence.

Another question remaining from the $\mathrm{CuO}$ discharge study ${ }^{3}$ was to determine the origin of a series of curious galvanostatic discharge profiles, in which upon exhaustion of $\mathrm{CuO}$ via Eqn. 1, the potential decreased for some time, before increasing by $\sim 0.2 \mathrm{~V}$ and reaching a plateau corresponding to discharge via Eqn. 2. That is, the discharge potential increased despite a cathodic current being applied the whole time. At the time this was speculated to be the result of the mechanism of Eqn. I - we can now return and give further attention to this phenomenon.

This manuscript has two aims; namely to (i) directly confirm the $\mathrm{CuO} \rightarrow \mathrm{Cu}_{2} \mathrm{O} \rightarrow \mathrm{Cu}^{\circ}$ pathway, and (ii) elucidate the mechanism of the $\mathrm{CuO} \rightarrow \mathrm{Cu}_{2} \mathrm{O}$ discharge step.

\section{Experimental}

Two CuO materials with vastly different physico-chemical properties were synthesized. The first was prepared via the room temperature conversion of a $\mathrm{Cu}(\mathrm{OH})_{2}$ precursor to $\mathrm{CuO}$. The precursor itself was prepared by a novel non-aqueous precipitation method. The method has been detailed elsewhere, but to recap here, involved the addition of $\mathrm{LiOH}$ dissolved in ethylene glycol, to a separate stirring glycolic $\mathrm{Cu}\left(\mathrm{NO}_{3}\right)_{2}$ solution in a $2.5: 1.0 \mathrm{LiOH}: \mathrm{Cu}\left(\mathrm{NO}_{3}\right)_{2}$ ratio. The resultant $\mathrm{Cu}(\mathrm{OH})_{2}$ suspension from the $\mathrm{Cu}^{2+}$ precipitation was stirred for $2 \mathrm{~h}$, before the addition of Milli-Q water (resistivity $>18.2 \mathrm{M} \Omega . \mathrm{cm}$ ). The suspension was then stirred for several days, during which time the color was observed to change from blue-green to brown, indicating the transformation to $\mathrm{CuO}$. The material was isolated by successive decanting steps, along with ethanol and acetone washes. The final drying step was performed at room temperature with ethanol, as even modest heating has been observed to be detrimental to electrode performance. Finally, the $-45 \mu \mathrm{m}$ fraction was collected by sieve. The second material was prepared via the solid-state thermal decomposition of $\mathrm{Cu}\left(\mathrm{NO}_{3}\right)_{2} \cdot 2.5 \mathrm{H}_{2} \mathrm{O}$ at $450^{\circ} \mathrm{C}$ for $24 \mathrm{~h}$. The final black material was ground with a mortar and pestle, and used without any further treatment. For brevity, the materials shall herein be referred to as glycol- and thermal-CuO, respectively.

The electrochemical cell and blackmix preparation have been described well before, ${ }^{6}$ and will only be summarized here. The cell is illustrated in Figure 1. Blackmixes were prepared by grinding with a mortar and pestle the active material (CuO), SFG6 graphite (Timcal) and $9.0 \mathrm{M}, 1.0 \mathrm{M}$ or $0.1 \mathrm{M} \mathrm{KOH}$ (Sigma-Aldrich) electrolyte in the mass ratio 0.1:1.0:0.2-0.3. After mixing the blackmixes were allowed to equilibrate overnight in sealed containers. The mass corresponding to $15 \mathrm{mg}$ of active material was then inserted into a Teflon-lined, gold coated stainless steel $\mathrm{C}$-sized battery can which comprises the working electrode (WE), onto which three layers of separator paper were placed. A stainless steel piston was inserted and the electrode compacted under I tonne, after which the piston was removed, a Perspex perforated disk slid into the can, and a stainless steel ring

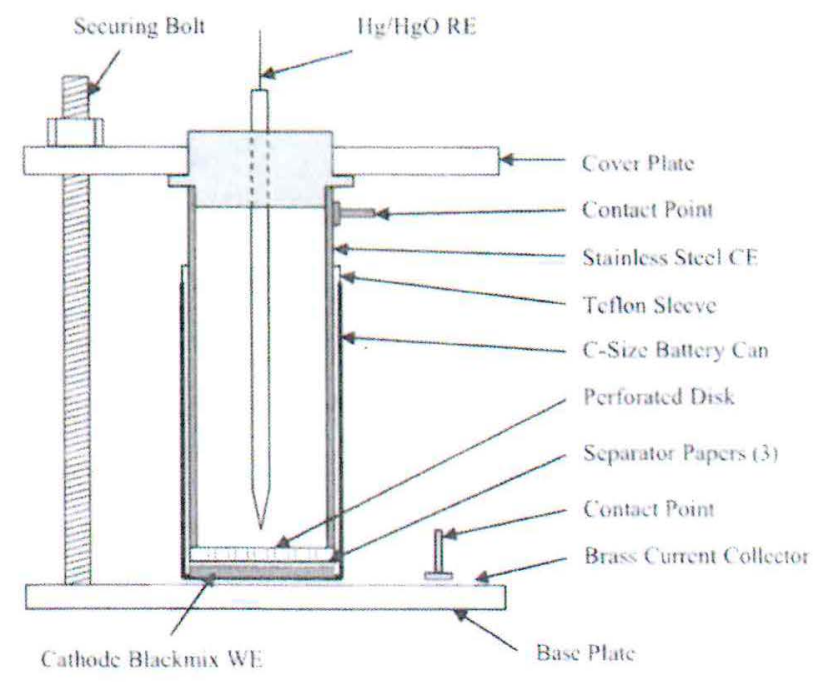

Figure 1. Electrochemical cell used for material evaluation 
counter electrode (CE) inserted. The cell was flooded with electrolyte $(\sim 15 \mathrm{~mL})$, and a home-made $\mathrm{Hg} / \mathrm{HgO}$ reference electrode (RE) inserted, the electrode constructed with $\mathrm{KOH}$ of the relevant electrolyte concentration.

Electrochemical measurements were carried out using a PerkinElmer VMP 16 channel potentiostat/galvanostat or a Solartron 1287 potentiostat/galvanostat. Linear sweep voltammetry was performed at a sweep rate of $0.02 \mathrm{mVs}^{-1}$ from the electrode open circuit potential (OCP) down to $-0.9 \mathrm{~V}$ versus the $\mathrm{Hg} / \mathrm{HgO}$ reference electrode. Galvanostatic discharge experiments were performed in the range of $50-2000 \mathrm{mAg}^{-1}$.

Powder X-ray diffraction patterns were collected on a Philips PW1710 diffractometer equipped with a $\mathrm{Cu} \mathrm{K}_{\alpha}$ radiation source $(\lambda=1.5418 \AA)$. The patterns were collected in the $2 \theta$ range $10-80^{\circ}$, with a $0.05^{\circ} 2 \theta$ step size and a $2 \mathrm{~s}$ count time.

Scanning electron micrograph (SEM) images were obtained with a Phillips XL30 SEM under a variety of magnifications on Au-coated samples.

Surface areas were obtained with a Micromeritics ASAP 2020 Surface Area and Porosity Analyser using a 5-point BET isotherm in the partial pressure range $0.05-0.30$ at $77 \mathrm{~K}$.

\section{Results and Discussion}

Physical Characterization.- The powder XRD patterns of the prepared $\mathrm{CuO}$ materials are given in Figure 2. Both samples index to tenorite $\mathrm{CuO}$ (JCPDS number 01-080-1916) although possess vastly different levels of crystallinity. As expected, the thermally-prepared thermal-CuO possesses a high level of crystallinity. This contrasts to the amorphous glycol-CuO, prepared via a soft precipitation/room temperature decomposition method.

Crystallite sizes were estimated via the Scherrer equation; i.e.,

$$
\mathrm{d}_{\mathrm{hkl}}=\frac{0.9 \lambda}{\beta \cos \theta}
$$

where $\mathrm{d}$ is the crystallite thickness $(\mathrm{nm})$ in the direction perpendicular to the diffraction plane, $\lambda$ is the wavelength of incident $X$-ray radiation $(\mathrm{nm}), \beta$ is the full-width half maximum of the peak (rad), and $\theta$ the diffraction angle (rad). The 0.9 is a shape fitting parameter, and is the most commonly used value. For the $(111)$ peak $(\sim 382 \theta)$ the

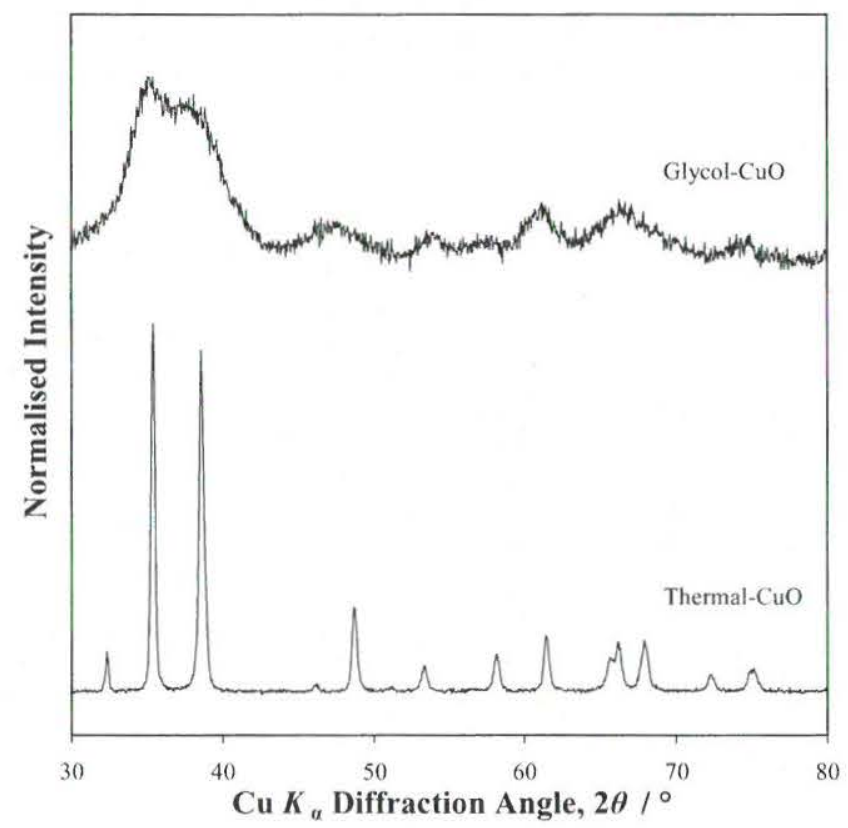

Figure 2. Powder X-ray diffraction patterns of the $\mathrm{CuO}$ materials of investigation.
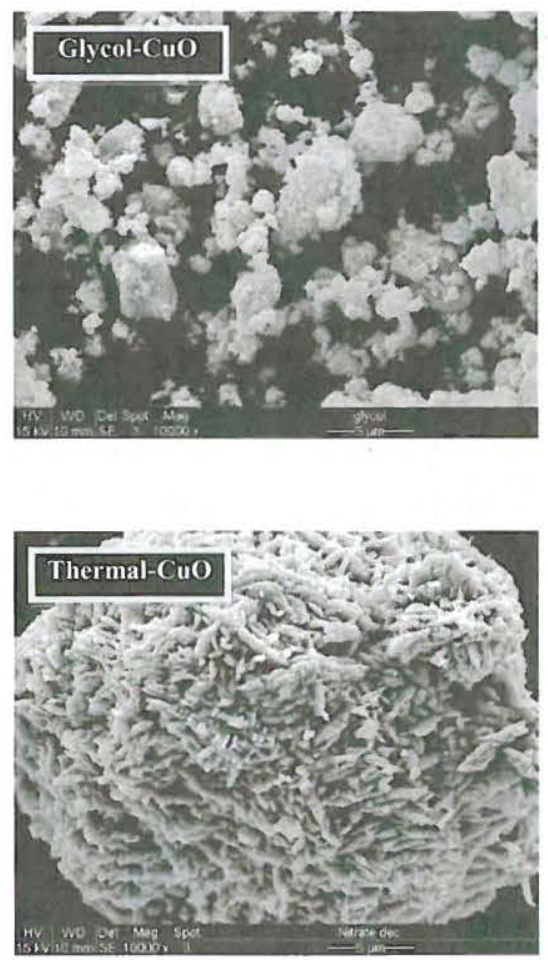

Figure 3. SEM micrographs of the $\mathrm{CuO}$ materials evaluated in this study.

crystallite thicknesses are 46.2 and $3.3 \mathrm{~nm}$ for thermal- and glycol$\mathrm{CuO}$, respectively. This is obviously a lower-limit for the glycol-CuO thickness, as some peak broadening will occur due to the high level of amorphicity which contributes toward the calculated thickness. Even taking this into account, it is clear that the crystallite size is much smaller for glycol-CuO compared to thermal-CuO.

The physico-chemical differences continue in SEM analysis of the materials, given in Figure 3. Thermal- $\mathrm{CuO}$ is present in large particles of $\sim 50 \mu \mathrm{m}$ size, which display some degree of sintering. Glycol-CuO in comparison displays a soft, cauliflower morphology, the origins of which were speculated upon in an earlier manuscript. Not surprisingly, the materials also display large differences in BET surface area, with 192 and $0.9 \mathrm{~m}^{2} \mathrm{~g}^{-1}$ determined for glycol- and thermal-CuO, respectively.

In summary, we have successfully prepared $\mathrm{CuO}$ materials with vastly different physico-chemical properties, which, as will be seen, may provide valuable insight into the electrochemical reduction mechanism of $\mathrm{CuO}$ in alkaline electrolyte conditions.

Electrochemical Characterization.- The linear sweep voltammetry of completed cells in a $9.0 \mathrm{M} \mathrm{KOH}$ electrolyte is given in Figure 4 . What is immediately apparent from the voltammograms is the markedly different mechanistic routes taken by the two materials. Amorphous glycol-CuO follows the previously-reported twin reduction process route, ${ }^{3-5}$ described in Eqns. 1 and 2. The voltammogram of the crystalline thermal-CuO displays a single sharp reduction peak at a unique voltage $(0.72 \mathrm{~V}$ vs. $\mathrm{Hg} / \mathrm{HgO})$. As this peak integrates approximately to the theoretical two-electron discharge capacity of $\mathrm{CuO}$ $\left(667 \mathrm{mAh}^{-1}\right)$, we propose the direct reduction reaction:

$$
\mathrm{CuO}+\mathrm{H}_{2} \mathrm{O}+2 \mathrm{e}^{-} \rightarrow \mathrm{Cu}^{0}+2 \mathrm{OH}^{-}
$$

Glycol-CuO Reaction Pathway.-We momentarily leave the different discharge pathways at face value to confirm the identity of the glycol$\mathrm{CuO}$ discharge intermediate. In our previous paper, ${ }^{3}$ we based our argument for discharge following the scheme Eqns 1 and 2 from a combination of evidences from the discharge capacity, the absence of $\mathrm{Cu}_{2} \mathrm{O}$ peaks in the original $\mathrm{CuO}$ XRD pattern, and from analogy with 


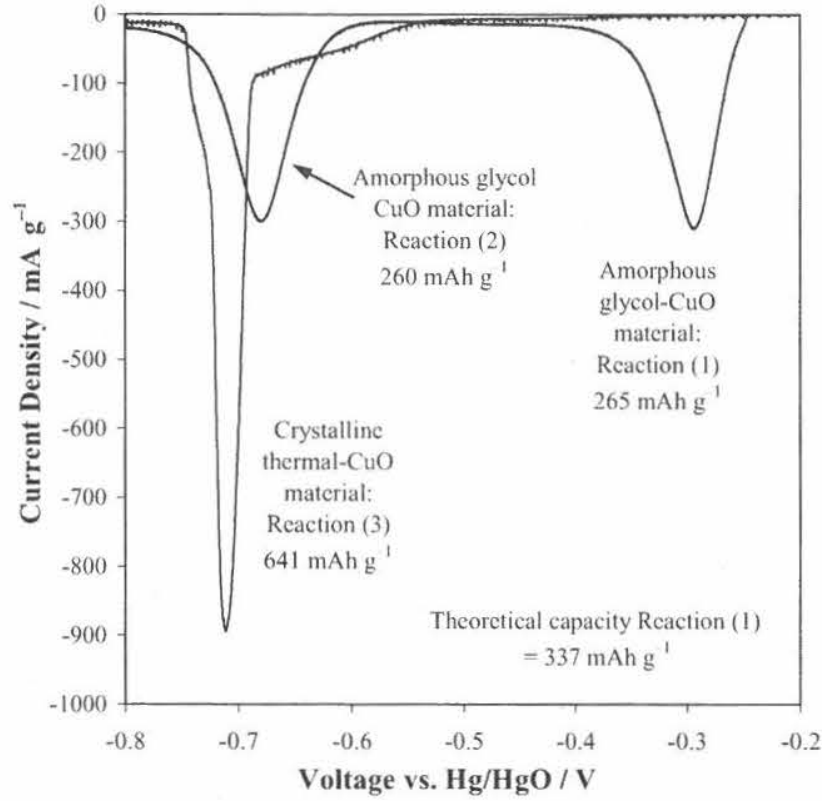

Figure 4. Linear sweep voltammogram of the $\mathrm{CuO}$ materials in $9.0 \mathrm{M} \mathrm{KOH}$ at $0.02 \mathrm{mV} \mathrm{s}^{-1}$.

$\mathrm{AgCuO}_{2}$ discharge. ${ }^{4}$ We may now present ex-situ confirmation of this pathway.

An electrochemical cell with a special blackmix composition $(\mathrm{CuO}: \mathrm{SFG}: \mathrm{KOH}=0.2: 1.0: 0.2)$ was constructed and discharged voltammetrically at $0.02 \mathrm{mVs}^{-1}$ to $-0.55 \mathrm{~V}$ vs. $\mathrm{Hg} / \mathrm{HgO}$. The cell was then disassembled and the blackmix collected. Excess electrolyte was decanted, and flushed with a small volume of Milli-Q water. The blackmix was then taken for ex-situ XRD analysis, which was performed on a Philips X'Pert diffractometer due to the increased capability for fast, high-resolution scans over the 1710 model. The pattern is given in Figure 5, and is truncated to accentuate the $\mathrm{Cu}_{2} \mathrm{O}$ peaks over those of the majority graphite phase. The pattern indexes

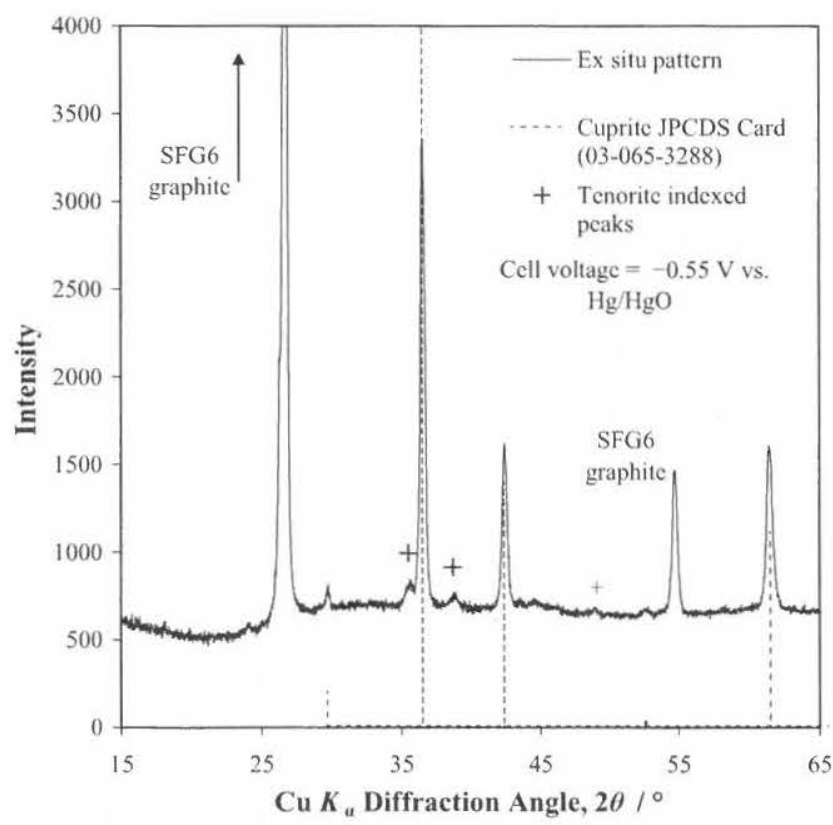

Figure 5. Ex situ XRD pattern of glycol-CuO discharged to $-0.55 \mathrm{~V}$ vs. $\mathrm{Hg} / \mathrm{HgO}$. Cuprite $\mathrm{Cu}_{2} \mathrm{O}$ and tenorite $\mathrm{CuO}$ peaks are indexed for comparison. to cuprite $\mathrm{Cu}_{2} \mathrm{O}$ (JCPDS 03-065-3288) confirming the $\mathrm{CuO} \rightarrow \mathrm{Cu}_{2} \mathrm{O}$ pathway. Extra peaks belong to graphite and residual tenorite $\mathrm{CuO}$, the latter from either re-oxidation of the $\mathrm{Cu}_{2} \mathrm{O}$ intermediate or incomplete reduction of $\mathrm{CuO}$.

Effect of Electrolyte Concentration.-Having confirmed the pathway undertaken by glycol-CuO, we may attempt to explain the underlying reasons for the vastly different reaction pathways. Before we do this, we again take a sojourn, this time to the performance of glycol-CuO in different concentration $\mathrm{KOH}$ electrolytes. The primary motivation for these experiments was the limitation or circumvention of cell gassing which would occur due to dissolution of $\mathrm{CuO}$ in alkaline electrolyte. As the dissolution is known to be concentration-dependent, we wished to evaluate the performance of the glycol-CuO cathode under lower $\mathrm{KOH}$ conditions. Secondary motivation revolves around shifting the potential, as predicted via application of the Nernst equation to Eqn. 1 . In performing these experiments, we have serendipitously uncovered valuable evidence for the mechanism of the $\mathrm{CuO} \rightarrow \mathrm{Cu}_{2} \mathrm{O}$ reaction. To avoid potential confusion, we have used the term pathway to describe the electrochemical half-reactions taking place, and have reserved the term mechanism to describe fundamental step-by-step path, which upon addition form the overall half-reactions. That is, we have established the overall pathway to be $\mathrm{CuO} \rightarrow \mathrm{Cu}_{2} \mathrm{O}$, but will uncover details of this half-reaction in the following study this reactions mechanism.

To compare voltammetry with electrolytes and reference electrodes constructed of different $\mathrm{KOH}$ concentrations, it is necessary to take into consideration the effect of $\mathrm{KOH}$ concentration (or more strictly, activity) on the redox potential of the $\mathrm{RE}$. The $\mathrm{Hg} / \mathrm{HgO} \mathrm{RE}$ reduction reaction is given by:

$$
\mathrm{HgO}+\mathrm{H}_{2} \mathrm{O}+2 \mathrm{e}^{-} \rightarrow \mathrm{Hg}^{0}+2 \mathrm{OH}^{-}
$$

The potential (E) of the reference electrode will be defined by the Nernst Equation,? substitution of Eqn. 5 into which yields

$$
\mathrm{E}=\mathrm{E}_{\mathrm{Hg} / \mathrm{HgO}}^{\mathrm{o}}+\frac{\mathrm{RT}}{2 \mathrm{~F}} \ln \left(\frac{\mathrm{a}_{\mathrm{HgO}} \cdot \mathrm{a}_{\mathrm{H}_{2} \mathrm{O}}}{\mathrm{a}_{\mathrm{Hg}} \cdot \mathrm{a}_{\mathrm{OH}^{-}}^{2}}\right)
$$

which reduces to

$$
\mathrm{E}=\mathrm{E}_{\mathrm{Hg} / \mathrm{HgO}}^{\mathrm{o}}-\frac{\mathrm{RT}}{\mathrm{F}} \ln \left(\mathrm{a}_{\mathrm{OH}^{-}}\right)
$$

assuming the activity (a) of the $\mathrm{Hg}$ and $\mathrm{HgO}$ phases and $\mathrm{H}_{2} \mathrm{O}$ solvent to be independent of $\mathrm{KOH}$ activity. The other variables have their conventional meanings; i.e., $\mathrm{E}^{\circ}$ is the standard reduction potential, $\mathrm{R}$ is the ideal gas constant $\left(8.314 \mathrm{JK}^{-1} \cdot \mathrm{mol}^{-1}\right)$, $\mathrm{T}$ the thermodynamic temperature $(\mathrm{K})$, and $\mathrm{F}$ is Faraday's constant $\left(96485.3{\mathrm{C} . \mathrm{mol}^{-1}}^{-1}\right)$. The activity of a species $\mathrm{X}$ is given by

$$
\mathrm{ax}_{\mathrm{x}}=\gamma_{ \pm}\left(\frac{\mathrm{c}}{\mathrm{c}^{\mathrm{o}}}\right)
$$

where $\gamma_{ \pm}$is the (geometric) mean activity coefficient of the species $\mathrm{X}$ for a strong $1: 1$ electrolyte, $\mathrm{c}$ its concentration, and $\mathrm{c}^{\circ}$ its standard concentration to preserve the unitless nature of the activity. ${ }^{8}$

We define the change in equilibrium reference electrode potential from that at $9.0 \mathrm{M} \mathrm{KOH}$ as $\mathrm{KOH}$ activity is changed as

$$
\Delta \mathrm{E}=\mathrm{E}_{9 \mathrm{M}}-\mathrm{E}_{\mathrm{xM}}
$$

Applying Eqn. 7 to Eqn. 9 gives

$$
\Delta \mathrm{E}=\frac{\mathrm{RT}}{\mathrm{F}} \ln \left(\frac{\mathrm{a}_{\mathrm{OH}^{-}, \mathrm{xM}}}{\mathrm{a}_{\mathrm{OH}^{-}, 9 \mathrm{M}}}\right)
$$

which gives us a convenient method for potential correction for voltammetry performed in different concentration electrolytes. Using Eqns. 9 and 10 we may correct the reference potential under different hydroxide activity back to that under $9 \mathrm{M} \mathrm{KOH}$ conditions.

The concentration-activity coefficient relationship for the common $\mathrm{KOH}$ electrolyte has been extensively mapped. ${ }^{9}$ The concentrationactivity relationship is illustrated in Figure 6, and follows an exponential trend. Within, we make use of the exponential relationship by 


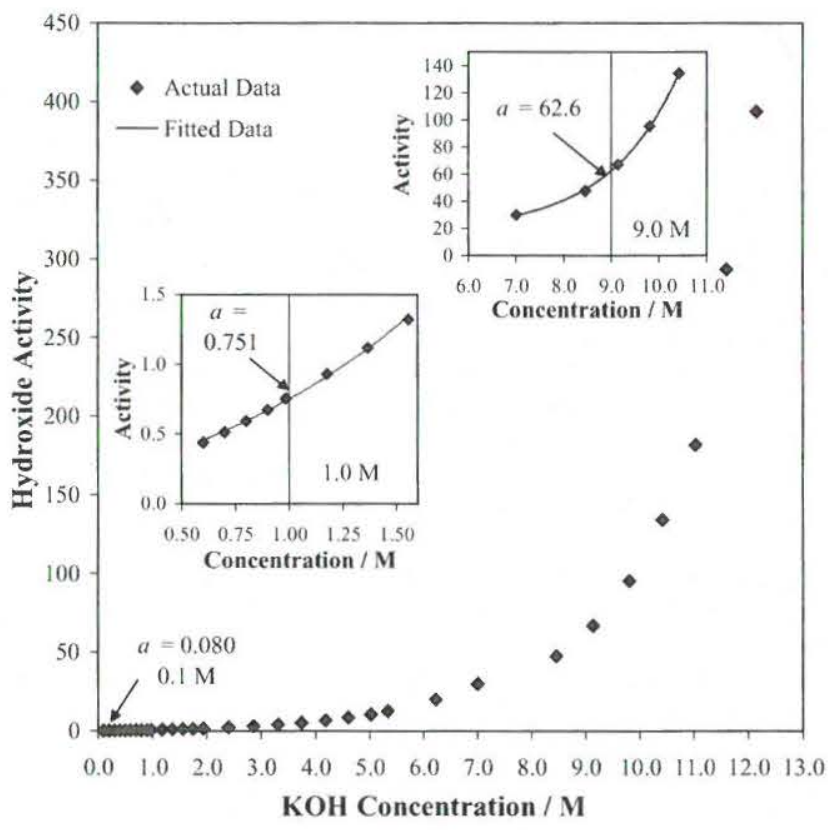

Figure 6. $\mathrm{KOH}$ concentration-activity relationship constructed from the literature ${ }^{9}$ and the interpolated activities at $[\mathrm{KOH}]=0.1 \mathrm{M}, 1.0 \mathrm{M}$ and $9.0 \mathrm{M}$

fitting a local exponential fit of the form

$$
\mathrm{ax}_{\mathrm{x}}=\mathrm{Ae}^{\mathrm{kc}}+\mathrm{D}
$$

to estimate the activity of $\mathrm{KOH}$ at each concentration used, where A, $\mathrm{k}$ and $\mathrm{D}$ are simple fitting parameters. From the local fitting of the model, we estimate activities of $\mathrm{KOH}$ to be $0.080,0.751$ and 62.36 at $0.1,1.0$ and $9.0 \mathrm{M}$ respectively. This corresponds to $\Delta \mathrm{E}$ of -0.114 and $-0.172 \mathrm{~V}$ for 1.0 and $0.1 \mathrm{M} \mathrm{KOH}$, to compare to that obtained with a $9.0 \mathrm{M} \mathrm{KOH} \mathrm{Hg/HgO} \mathrm{RE.}$

Corrected discharge profiles of glycol-CuO at a current density of $200 \mathrm{mAg}^{-1}$ as a function of electrolyte concentration are given in Figure 7, and discharge capacity-discharge rate data in Figure 8.

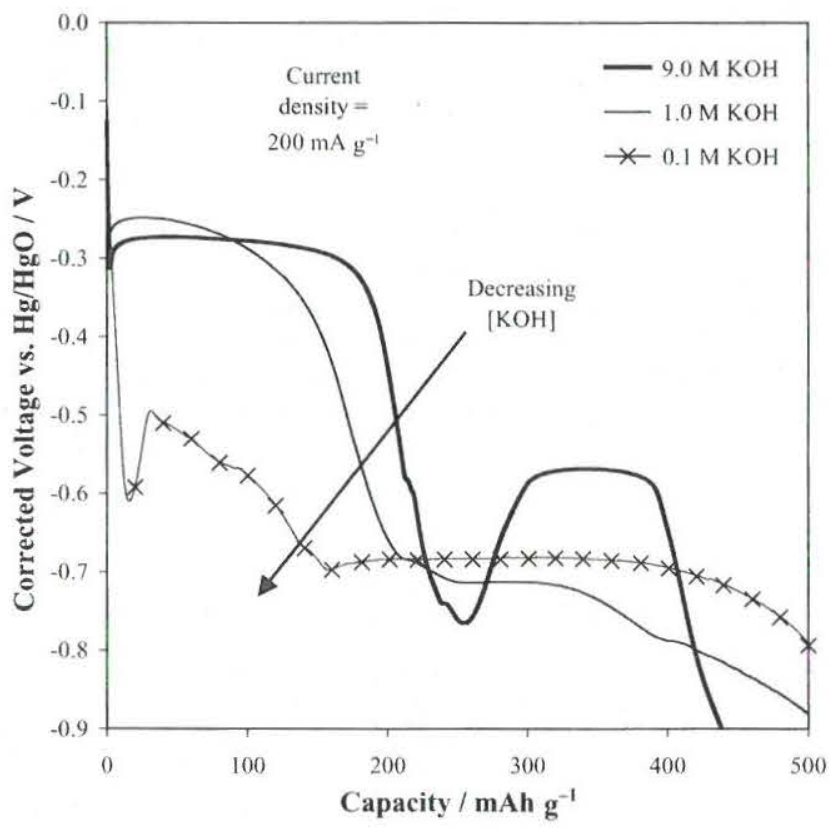

Figure 7. Voltage-corrected discharge profiles of glycol-CuO in 9.0,1.0 and $0.1 \mathrm{M} \mathrm{KOH}$ electrolyte at $200 \mathrm{~mA} \mathrm{~g}^{-1}$

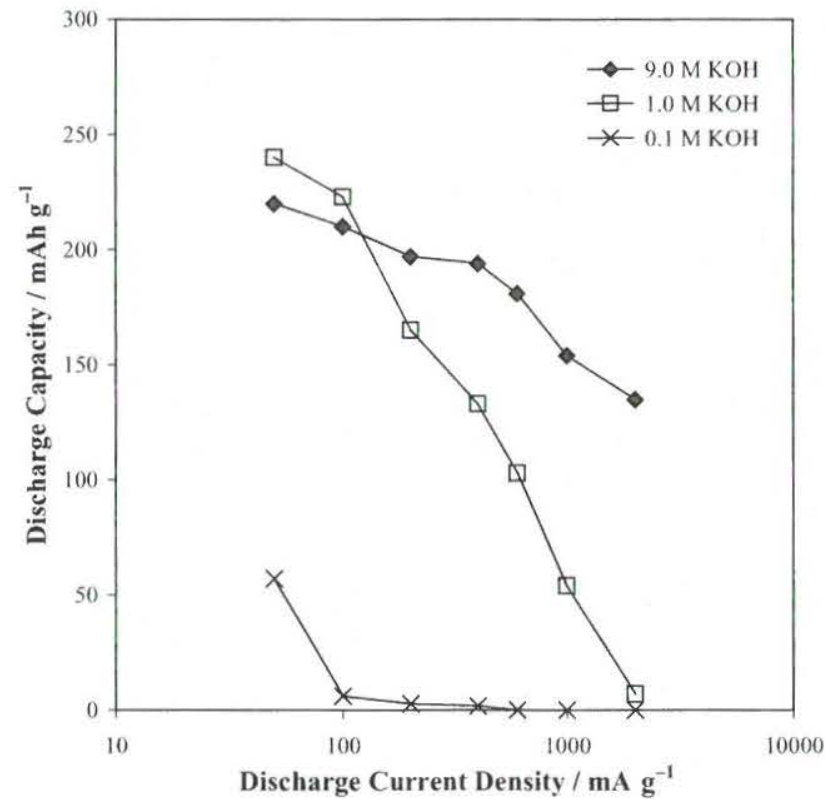

Figure 8. Capacity-current density data of the glycol CuO material in 9.0,1.0 and $0.1 \mathrm{M} \mathrm{KOH}$ electrolyte.

What is immediately obvious from either plot is the strong dependence of discharge performance on electrolyte concentration. We had previously speculated that decreased electrolyte concentration may have a positive impact on discharge performance, by both raising the potential of the electrode via the Nernst equation and through increased stability due to lower solubilization of the active $\mathrm{CuO}$ material. We instead have uncovered a strong dependence of performance on electrolyte concentration, where performance is superior with high $\mathrm{KOH}$ concentration electrolytes, and the electrode fails with a $0.1 \mathrm{M}$ $\mathrm{KOH}$ electrolyte at moderate discharge rates. For the high rate performance observed in ${ }^{3}$ to be realized requires a high $\mathrm{KOH}$ concentration electrolyte.

The contrary evidence of increased capacity in a $1.0 \mathrm{M} \mathrm{KOH}$ electrolyte over that in $9.0 \mathrm{M} \mathrm{KOH}$ when the discharge rate is $<200$ $\mathrm{mA} . \mathrm{g}^{-1}$ deserves some attention. One explanation may be due to an expected increased rate of competitive dissolution of $\mathrm{CuO}$ in $9.0 \mathrm{M}$ $\mathrm{KOH}$ than in $1.0 \mathrm{M} \mathrm{KOH}$ decreasing the active mass. ${ }^{10}$ This would especially be expected at lower discharge rates, as there is comparatively more time allowed for this process to take place.

Reduction Mechanism of Eqn (1).- As all electrolytes have $\mathrm{KOH}$ concentrations sufficiently high for adequate conductivity, ${ }^{11,12}$ the observed performance trends must emanate from some other phenomena. As performance improves with increasing $\mathrm{KOH}$ concentration, it is possible that the strength of the hydroxide solution plays some role. As it is well-known that soluble species formation is $\left[\mathrm{OH}^{-}\right]$dependent, ${ }^{10}$ it is possible that there is a solubilization step in the $\mathrm{CuO} \rightarrow \mathrm{Cu}_{2} \mathrm{O}$ mechanism.

Entertaining this tentative hypothesis briefly allows us to explain the performance data. Where the activity of hydroxide is too low (i.e., $0.1 \mathrm{M} \mathrm{KOH}$ ) to actively assist in a solubilization step in the mechanism, the electrode fails and discharges via a lower potential process (see Figure 7). Where the activity is high enough to facilitate the solubilization step, the reduction follows the two-step pathway.

This hypothesis also allows for adequate interpretation of the shape of the discharge profiles shown. Figure 9 has replicated the $200 \mathrm{mAg}^{-1}$ discharge profile in $9.0 \mathrm{M} \mathrm{KOH}$, with a species annotation at each region of the profile. This represents the potential-determining species at each step in the mechanism. Consider the potential trough present after the exhaustion of $\mathrm{CuO}$, and before the plateau for $\mathrm{Cu}_{2} \mathrm{O}$ reduction at $-0.57 \mathrm{~V}$. The phenomena of interest is that the potential 


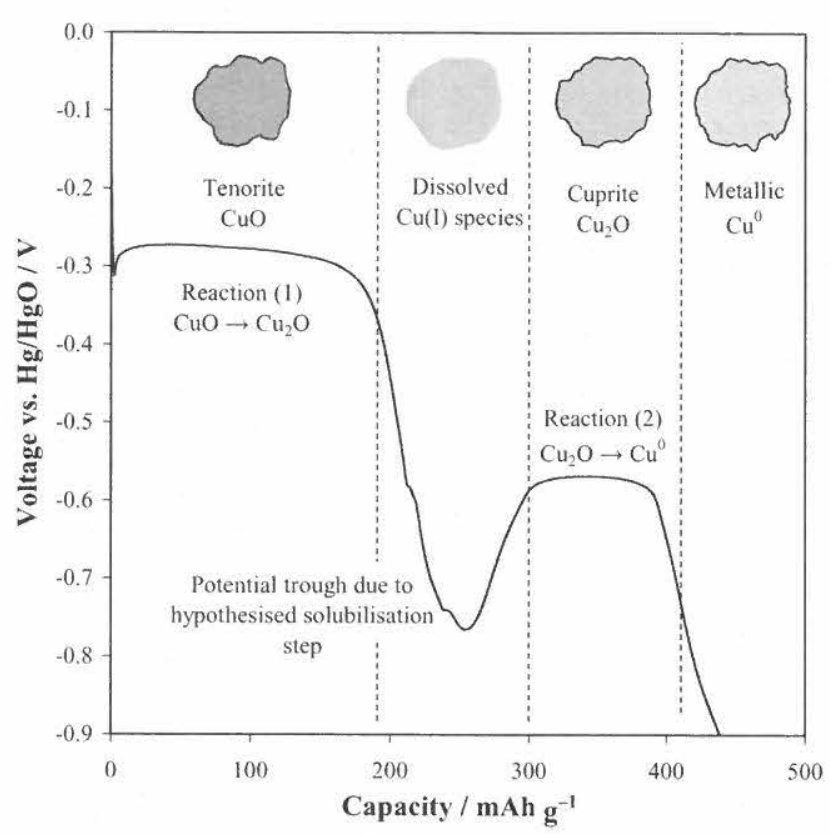

Figure 9. Discharge profile of glycol-CuO at $200 \mathrm{~mA} \mathrm{~g}^{-1}$ in $9.0 \mathrm{M} \mathrm{KOH}$ annotated with the proposed voltage-determining species at each point in the profile.

can increase despite a cathodic current being applied throughout. We propose that this effect originates from speciation. Consider a mechanism whereby a soluble species forms during discharge of $\mathrm{CuO}$, and that the soluble $\mathrm{Cu}(\mathrm{I})$ species can saturate the electrode to such an extent that upon exhaustion of $\mathrm{CuO}$ it is potential-determining. A switch in $\mathrm{Cu}(\mathrm{I})$ species from a soluble one to a higher potential $\mathrm{Cu}_{2} \mathrm{O}$ cuprite phase could explain the shape of the discharge profile. The nucleation of the $\mathrm{Cu}_{2} \mathrm{O}$ phase from a soluble $\mathrm{Cu}(\mathrm{I})$ species brings about the potential recovery, and is assumedly concentration-dependent.

We therefore have two good indirect reasons to be confident that the proposed mechanism is correct. In order to unequivocally show that $\mathrm{CuO}$ reduction undergoes a solubilization/re-precipitation mechanism, we must experimentally detect the soluble intermediate. A method for detecting such a soluble species has been previously developed within our laboratory for $\mathrm{MnO}_{2}$ discharge. ${ }^{13}$ A soluble $\mathrm{Mn}(\mathrm{III})$ species was detected electrochemically as an anodic current at a near in-situ Pt loop detector electrode. We performed the experiment applying the same methodology to our $\mathrm{CuO}$ system. A conventional discharge cell was prepared, with the exception that only one separator paper was used instead of three. Above this, a Pt wire loop detector electrode was placed, with the perforated disk holding it firm in contact above the insulating separator. Two channels on the potentiostat were employed, with both channels sharing a common reference and counter electrode. The working electrode underwent a typical $200 \mathrm{mAg}^{-1}$ discharge regime after a 20 min rest time. The Pt loop detector electrode was stepped to and held at $+0.05 \mathrm{~V}$ vs. $\mathrm{Hg} / \mathrm{HgO}$. Figure 10 shows the results of this experiment. During the 20 min rest time, the capacitive current at the detector electrode decays to $\sim 1.5$ $\mu \mathrm{A}$. Upon commencement of the galvanostatic discharge regime, the potential of the working electrode drops from the open circuit potential to the working potential of $\mathrm{CuO}$ discharge via Eqn. 1. Simultaneously, the detector current jumps by $\sim 1 \mu \mathrm{A}$, corresponding to the oxidation of a soluble $\mathrm{Cu}(\mathrm{I})$ intermediate and confirming the proposed solubilization/reprecipitation mechanism. The anodic detector current peaked after $40 \mathrm{~s}$ into the discharge regime. Estimating the thickness of the separator paper to be $\sim 25 \mu \mathrm{m}$ gives an estimated diffusion coefficient for $\mathrm{Cu}(\mathrm{I})$ of $1.6 \times 10^{-7} \mathrm{~cm}^{2} \cdot \mathrm{s}^{-1}$. There is no chance for the oxidation of $\mathrm{Cu}_{2} \mathrm{O}$, as the detector electrode is physically isolated from this via the separator paper.

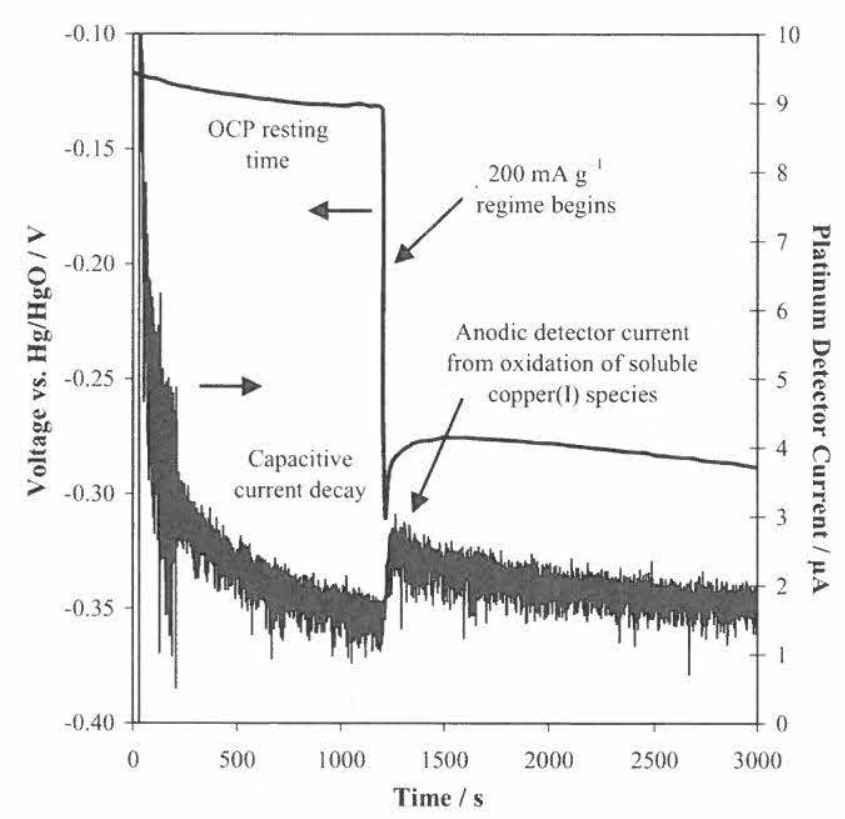

Figure 10. Near-in situ electrochemical detection of a soluble $\mathrm{Cu}(\mathrm{I})$ intermediate in discharge of $\mathrm{CuO} \rightarrow \mathrm{Cu}_{2} \mathrm{O}$.

This confirmation opens up another question regarding the discharge mechanism - does the mechanism proceed by the solubilization of a reduced species, followed by its precipitation, or does the solubilization precede the reduction? That is, using the convention in electrochemical mechanisms of using the letter $\mathrm{E}$ to describe an electrochemical step (charge transfer) and the letter $\mathrm{C}$ to describe a chemical step (solubilization), does the reaction proceed via an ECC or $\mathrm{CEC}$ mechanism? (The final $\mathrm{C}$ is the nucleation of $\mathrm{Cu}_{2} \mathrm{O}$, which is common to both mechanisms.) These options are illustrated in Figure 11. In a $\mathrm{CEC}$ mechanism, the soluble $\mathrm{Cu}$ (II) species - likely the $\mathrm{Cu}(\mathrm{OH})_{4}{ }^{2-}$ ion $^{10}$ - would be reduced at the surface of the SFG6

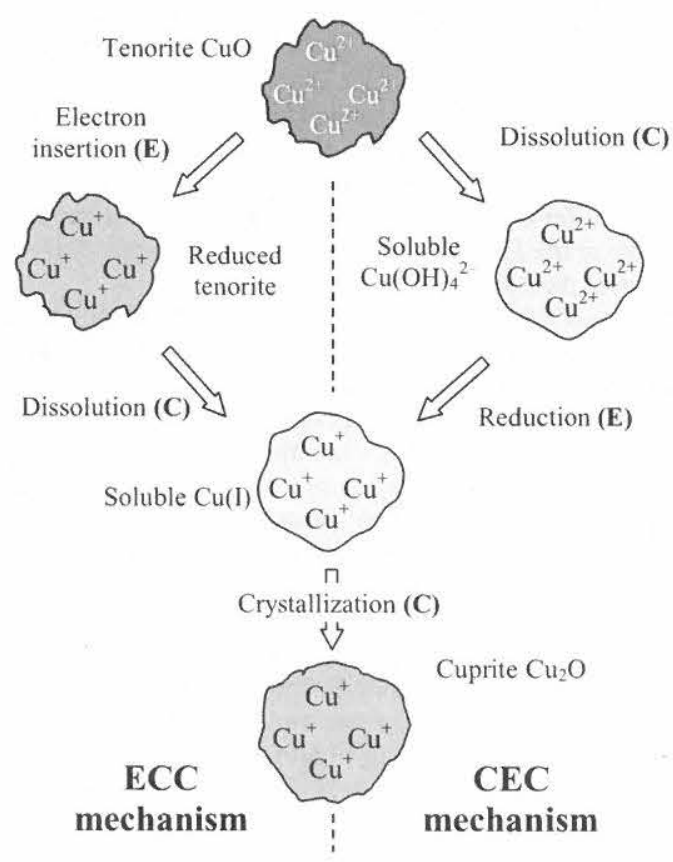

Figure 11. The two different solubilization-crystallization mechanisms proposed for Reaction 1; an ECC and CEC mechanism. 


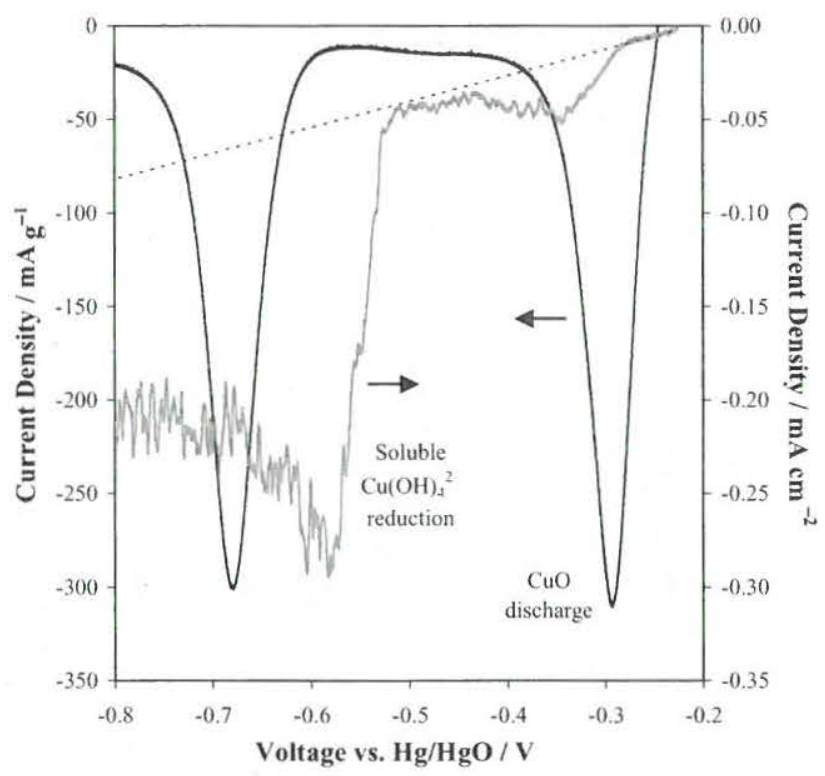

Figure 12. LSV of solid tenorite $\mathrm{CuO}$ vs. LSV of $\mathrm{Cu}(\mathrm{OH})_{4}{ }^{2-}$ at a glassy carbon electrode in $9.0 \mathrm{M} \mathrm{KOH}$.

graphite. This question opens up a simple experiment to choose between the two mechanisms - simply to dissolve $\mathrm{CuO}$ in $9.0 \mathrm{M} \mathrm{KOH}$ and to reduce the soluble species via a conventional solution-based voltammetry experiment. A matching reduction potential in solution would be good evidence that the discharge mechanism follows a CEC mechanism, and what we are actually reducing is the soluble species. This experiment was performed with a glassy carbon working electrode at $0.02 \mathrm{mVs}^{-1}$, with the results given in Figure 12, along with the results of a conventional solid-state $\mathrm{CuO}$ voltammogram. Glycol-CuO dissolved immediately to form the soluble species. Thermal-CuO did not dissolve appreciably to form a blue solution, even after being left overnight. This suggests a role of crystallinity in stability, rather than simply a surface area-proportional dissolution reaction. Clearly the reduction potentials of $\mathrm{CuO}$ and alkaline soluble $\mathrm{Cu}(\mathrm{OH})_{4}{ }^{2-}$ do not overlap, which is evidence against the CEC mechanism. The origin of the minor voltammetric peak at $-0.4 \mathrm{~V}$ is unknown, and is potentially ascribable to an electrode surface impurity. The shape of the major peak is consistent with the assignment to that of $\mathrm{Cu}(\mathrm{OH})_{4}{ }^{2-}$ reduction, provided the reduction occurs to electrodeposition of metallic $\mathrm{Cu}^{0}$. The sharp shape of the peak can be explained if $\mathrm{Cu}(\mathrm{OH})_{4}{ }^{2-}$ reduction kinetics are faster on $\mathrm{Cu}$ than on glassy carbon. For these reasons, we therefore favor the ECC mechanism to describe the discharge of $\mathrm{CuO}$ $\rightarrow \mathrm{Cu}_{2} \mathrm{O}$ over the $\mathrm{CEC}$ option.

Invoking a solubilization mechanism for $\mathrm{CuO}$ reduction under alkaline conditions may have explanatory powers beyond the current case. A recent communication concerned the quantitative determination of $\mathrm{CuO}$ beyond sub- $\mu \mathrm{g}$ levels by a voltammetric method in 0.1 $\mathrm{M} \mathrm{NaOH}$ electrolyte ${ }^{14}$. In this work the authors note a two-step reduction pathway, in which they reason that the capacity of the lower potential peak had contributions from both reduction of $\mathrm{Cu}_{2} \mathrm{O}$ (by Eqn. 2) and direct reduction of $\mathrm{CuO}$ to $\mathrm{Cu}^{0}$ (Eqn. 4). The CuO itself was leftover from incomplete reduction of $\mathrm{CuO}$ to $\mathrm{Cu}_{2} \mathrm{O}$. This is consistent with the solubilization mechanism presented here. $\mathrm{CuO}$ is not reduced completely as the hydroxide activity of the electrolyte is not high enough to support the solubilization process. The remaining active material discharges at a lower potential, which is what is observed in the galvanostatic discharge of Figure 7.
Effect of Material Properties on Discharge Pathway-We are now equipped at last to return to the observation of the different discharge pathways followed by the glycol-CuO thermal-CuO materials presented in Figure 4. The discharge mechanism of Eqn. 1 requires a solubilization step which would be kinetically hindered in the bulky, sintered, low surface area thermal-CuO material. Assumedly, the increased thermodynamic stability afforded by a high level of crystallinity also inhibits the solubilization step. This is consistent with the anecdotal evidence presented for the preparation of soluble $\mathrm{Cu}(\mathrm{OH})_{4}{ }^{2-}$, where glycol-CuO dissolved immediately whereas thermal-CuO did not, even after being left in $9.0 \mathrm{M} \mathrm{KOH}$ overnight. With Eqn. 1 - and therefore Eqn. 2 - unavailable to the material due to poor solubilization kinetics, the material discharges via a different pathway, the single-step pathway presented in Eqn. 4. A similar pathway is utilized by glycol-CuO under $0.1 \mathrm{M} \mathrm{KOH}$ electrolyte conditions, as illustrated in the $200 \mathrm{mAg}^{-1}$ galvanostatic discharge data presented in Figure 7. In this case, Eqn. 1 is restricted by the low hydroxide activity of the electrolyte, rather than poor solubilization properties intrinsic to the material.

\section{Conclusions}

Amorphous $\mathrm{CuO}$ is confirmed to discharge via $\mathrm{Cu}_{2} \mathrm{O}$ intermediate in strongly alkaline electrolyte. The mechanism of intermediate formation was confirmed to involve a solubilization step. The lability of the formation of the soluble intermediate dictates the electrode performance, or in extreme cases of low $\mathrm{OH}^{-}$activity, the actual discharge pathway followed.

From these results, we anticipate that for the purposes of high rate performance that both a high surface area material and concentrated alkaline electrolyte are required. A high level of amorphicity may also be favorable, as the rate of solubilization of the pristine glycol$\mathrm{CuO}$ is much higher than that of thermal-CuO. This finding may be troublesome for the alkaline $\mathrm{CuO}$ cathode, as the solubilization of $\mathrm{CuO}$ presents a cell gassing problem.

\section{Acknowledgments}

The authors acknowledge the technical support of Dave Phelan and Jenny Zobec from the University of Newcastle Electron Microscope and X-Ray unit.

\section{References}

1. M. F. Mansuetto and A. Webber, "Cell with Copper Oxide Cathode" US Patent Number 7,465,518.

2. D. L. Anglin, J. S. Xue, and F. P. Wang, "Alkaline Cell with Improved Cathode" US Patent Number 6,841,302.

3. T. W. Jones, A. P. Lewandowski, and S. W. Donne, Electrochim. Acta, 56, 4996 (2011).

4. C. Eylem, N. Iltchev, K. Nanjundaswamy, and F. Wang, Electrochem. Solid-State Lett., 7, A346 (2004).

5. T. W. Jones, J. S. Forrester, A. Hamilton, M. G. Rose, and S. W. Donne, J. Power Sources, 172, 962 (2007).

6. A. P. Malloy, G. J. Browning, and S. W. Donne, J. Colloid. Interfac. Sci, 285, 653 (2005).

7. A. J. Bard and L. F. Faulkner, Electrochemical Methods: Fundamentals and Applications, 2nd Ed., p.52, John Wiley \& Sons (2001).

8. P. W. Atkins and J. de Paula, Physical Chemistry, 7th Ed., p. 257, Oxford University Press (2001).

9. R. A. Robinson and R. H. Stokes, Trans. Faraday Soc., 45, 612 (1949)

10. Y. Cudennec and A. Lecerf, Solid State Sci., 5, 1471 (2003).

11. C. Iwakura, S. Nohara, N. Furukawa, and H. Inoue, Solid State lonics, 148, 487 (2002).

12. R. J. Gilliam, J. W. Graydon, D. W. Kirk, and S. J. Thorpe, Int. J. Hydrogen Energ. 32, 359 (2007).

13. S. W. Donne, G. A. Lawrence, and D. A. J. Swinkels, J. Electrochem. Sec, 144, 2961 (1997).

14. W. T. Zeo, A. Ambrosi, and M. Pumera, Elecrochem. Commun., 28, 51 (2013). 